\title{
Betanin prohibits cisplatin-induced nephrotoxicity through targeting mitochondria
}

\author{
Sepideh ZUNUNI VAHED ${ }^{1}$ (D), Mohammadreza ARDALAN 1 (D), Rovshan KHALILOV 2, 3,4 (D), Elham \\ AHMADIAN 1,5* (D) \\ 1 Kidney Research Center, Tabriz University of Medical Sciences, Tabriz, Iran. \\ 2 Russian Institute for Advanced Study, Moscow State Pedagogical University, 1/1, Malaya Pirogovskaya St., \\ Moscow, Russian Federation 119991. \\ 3 Department of Biophysics and Molecular Biology, Baku State University, Baku, Azerbaijan. \\ 4 Joint Ukraine-Azerbaijan International Research and Education Center of Nanobiotechnology and Functional \\ Nanosystems, Drohobych Ukraine \& Baku, Azerbaijan. \\ 5 Students Research Committee, Tabriz University of Medical Sciences, Tabriz, Iran. \\ * Corresponding Author. E-mail: ahmadian.elham@yahoo.com (E.A.); Tel. +98-914-445 4094.
}

Received: 09 August 2019 / Revised: 23 September 2019 / Accepted: 05 October 2019

\begin{abstract}
Cisplatin is a common chemotherapeutic agent against a wide range of solid tumors. The clinical application of cisplatin is restricted due to its adverse effect, mainly nephrotoxicity. The aim of this study was to examine whether betanin (a natural pigment) is able to alleviate cisplatin-induced renal injury. Rats received cisplatin (10 mg/ $\mathrm{kg}$, single dose) after 3 consecutive days of betanin $(100 \mathrm{mg} / \mathrm{kg})$ oral gavage. Serum and urine samples were collected and kidney mitochondria were isolated from the treated groups for the further evaluations. Cisplatin-treated animals revealed altered biochemical evidence of nephrotoxicity, which were significantly improved in betanin pre-treated groups. On the other hand, betanin modulated mitochondrial parameters such as mitochondrial dehydrogenase activity, mitochondrial swelling, mitochondrial ATP content, mitochondrial depolarization, lipid peroxidation, and cytochrome c release. These data propose the possible protective role of betanin in cisplatin-associated nephrotoxicity in which the mechanism appears to be a prohibition of chemical disturbances and mitochondrial damage.
\end{abstract}

KEYWORDS: Cisplatin; mitochondria; betanin; nephrotoxicity; kidney.

\section{INTRODUCTION}

Drug-induced nephrotoxicity is a major concern in contribution to kidney diseases. It has been shown that a diverse group of drugs/xenobiotics can induce disturbances in the chemical transport of the proximal renal tubules, which in turn results in the variation of serum electrolytes and an abnormal amount of several chemicals such as proteins, glucose and amino acids in the urine [1-3]. In spite of the well-recognized clinical manifestations, the comprehensive underlying mechanisms of drug-induced renal injury remain vague. Cisplatin, cisplatinum or cis-diamminedichloroplatinum (II), is one of the most frequently used anticancer drugs and a large spectrum of solid tumors have benefited from its pharmacological effects. Although the drug is more effective in higher doses, dose increment is restricted due to the concentration-dependent toxic effects, mainly renal toxicity $[4,5]$. The use of pharmacological/osmotic diuresis and hydration strategies can tackle this nephrotoxicity. However, $30 \%$ of the patients who have a cisplatin-based treatment regimen still show irreversible renal injuries [6,7]. Clues coming from the literature search propose that the generation of the reactive oxygen species (ROS) has a critical and causative role in cisplatin-related nephrotoxicity $[8,9]$. Mitochondria as pipelines of cellular energy metabolism are the fundamental sources of intracellular ROS production. Interestingly, mitochondria are the main target of xenobiotic-induced toxicities and also many other pathologies [10,11]. Mitochondrial damages have been reported in cisplatin-induced toxicity [12]. The use of antioxidants has grabbed great attention to provide a robust defense system against drug-associated mitochondropathy [13-17]. Betanin (betanidin 5-O- $\beta$-D-glucoside) as the most abundant constituents of betalain, is a naturally accruing compound with prominent antioxidant and anti-inflammatory effects [18]. Different in vitro and in vivo studies have indicated the excellent antioxidant effects of betanin and betalanins

How to cite this article: Zununı Vahed S, Ardalan M, Khalilov R, Ahmadian E. Betanin prohibits cisplatin-induced nephrotoxicity through targeting mitochondria. J Res Pharm. 2019; 23(6): 1131-11399. 
against different kind of toxicities [13,18]. This free radical scavenging effect is due to the presence of phenolic and cyclic amine groups in their structure which are well-known electron donors [13]. The protective role of betanin against glomerular and tubular kidney damages have been documented in the literature [18]. Moreover, the benefical role of betanin could be effective in prevention and treatment of cancer $[13,18]$. Betalains are extracted from Beta vulgaris var. rubra and are used in cosmetics, pharmaceutical, and food products as colorants [13]. Thus, the current study was designed to investigate the potential protective role of betanin on renal mitochondria in cisplatin-treated rats.

\section{RESULTS}

The results of the current study demonstrated that cisplatin alters the urine (glucose, gamma-glutamyl transferase $(\gamma-\mathrm{GT})$, and total protein) and serum (glucose, total protein, creatinine, and blood urea nitrogen; BUN) biomarkers as biochemical indicators of renal injury. In addition, administration of betanin could significantly improve renal function by correction of chemical reabsorption process (Tables $1 \& 2$ ).

Table 1. The effect of betanin in urine biomarkers of cisplatin-treated animals.

\begin{tabular}{|c|c|c|c|c|}
\hline Urine samples & Control & $\begin{array}{c}\text { Betanin } \\
(100 \mathrm{mg} / \mathrm{kg})\end{array}$ & $\begin{array}{l}\text { Cisplatin } \\
(10 \mathrm{mg} / \mathrm{kg})\end{array}$ & $\begin{array}{c}\text { Betanin }(100 \mathrm{mg} / \mathrm{kg})+ \\
\text { Cisplatin }(10 \mathrm{mg} / \mathrm{kg})\end{array}$ \\
\hline Glucose (mg/dL) & $71 \pm 2$ & $69 \pm 4$ & $126 \pm 5^{a}$ & $82 \pm 3^{b}$ \\
\hline Protein $(\mathrm{mg} / \mathrm{dL})$ & $0.49 \pm 0.2$ & $0.47 \pm 0.1$ & $1.28 \pm 0.5^{\mathrm{a}}$ & $0.69 \pm 0.4^{b}$ \\
\hline$\gamma-\mathrm{GT}(\mathrm{U} / \mathrm{I})$ & $2012 \pm 258$ & $2009 \pm 374$ & $2401 \pm 196^{a}$ & $2024 \pm 217 b$ \\
\hline
\end{tabular}

Although cisplatin reduced total body weight and increased the kidney/ body weight ratio, the results were not significant (Table 2).

Table 2. The effect of betanin in alteration of total body weight (wt) and kidney body wt ratio and serum biomarkers in cisplatin-induced nephrotoxicity.

\begin{tabular}{|c|c|c|c|c|}
\hline & Control & $\begin{array}{c}\text { Betanin } \\
(100 \mathrm{mg} / \mathrm{kg})\end{array}$ & $\begin{array}{l}\text { Cisplatin } \\
(10 \mathrm{mg} / \mathrm{kg})\end{array}$ & $\begin{array}{c}\text { Betanin }(100 \mathrm{mg} / \mathrm{kg})+ \\
\text { Cisplatin }(10 \mathrm{mg} / \mathrm{kg})\end{array}$ \\
\hline BUN (mg/dL) & $4.4 \pm 0.6$ & $4.4 \pm 0.5$ & $7.8 \pm 0.3^{\mathrm{a}}$ & $5.2 \pm 0.9 \mathrm{~b}$ \\
\hline Creatinine (mg/dL) & $0.7 \pm 0.4$ & $0.69 \pm 0.3$ & $1.89 \pm 0.4^{\mathrm{a}}$ & $1.24 \pm 0.2^{b}$ \\
\hline Protein $(\mathrm{mg} / \mathrm{dL})$ & $7.3 \pm 0.2$ & $7.4 \pm 0.1$ & $6.4 \pm 0.6^{\mathrm{a}}$ & $6.7 \pm 0.3^{b}$ \\
\hline Glucose (mg/dL) & $112 \pm 4$ & $113 \pm 5$ & $87 \pm 2^{a}$ & $104 \pm 6^{b}$ \\
\hline$\Delta$ Total body wt ( $\%)$ & $100 \pm 3$ & $98 \pm 2$ & $94 \pm 4$ & $96 \pm 5$ \\
\hline Kidney/ body wt ratio & $5.1 \pm 0.3$ & $5.2 \pm 0.4$ & $5.6 \pm 0.6$ & $5.4 \pm 0.4$ \\
\hline
\end{tabular}

BUN: blood urea nitrogen.

a A significant difference compared to control $(\mathrm{p}<0.05)$.

$\mathrm{b}$ A significant difference compared to cisplatin-treated group $(\mathrm{p}<0.05)$.

A noticeable fall was observed in the mitochondrial dehydrogenase activity in cisplatin-treated group, whereas betanin $(100 \mathrm{mg} / \mathrm{kg}$ ) affected the enzyme activity in an upward trend (Figure 1).

The other assessments in the mitochondrial fractions of cisplatin-received group revealed a marked elevation of mitochondrial swelling, depolarization, and lipid peroxidation while the mitochondrial ATP content was significantly decreased (Figures $2 \& 3$ ). 


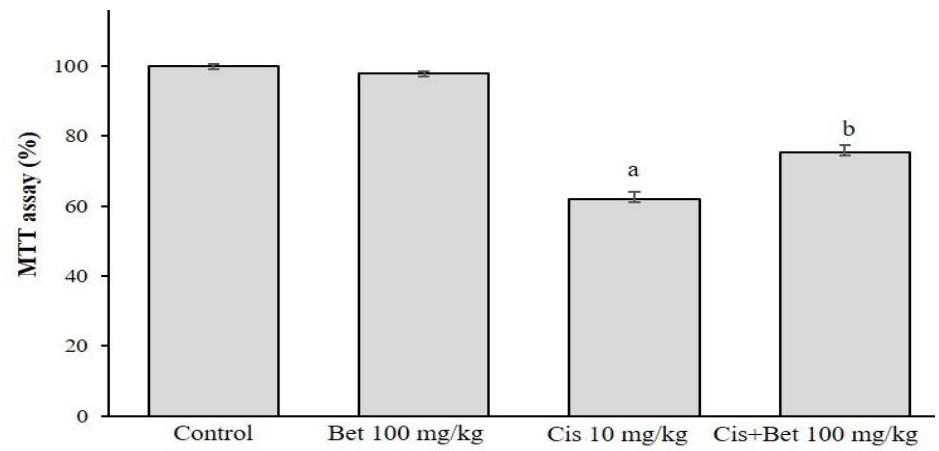

Figure 1. The role betanin (BET) on cisplatin (Cis)-induced changed in dehydrogenase enzyme activity in mitochondrial indices. Data are given as mean \pm SD $(n=10)$. aA significant difference compared to control. ${ }^{b}$ A significant difference compared to cis-treated group $(p<0.05)$.
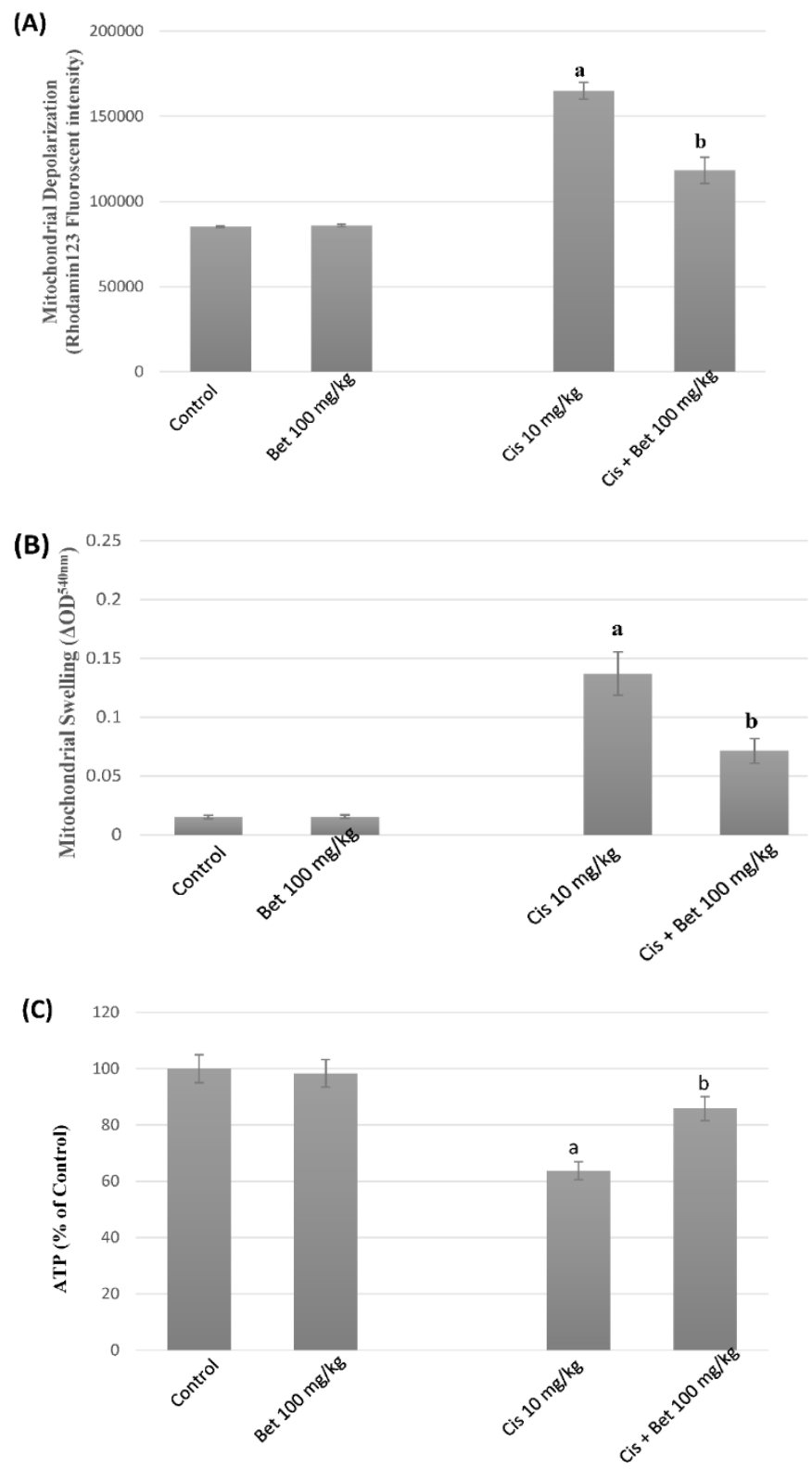

Figure 2. The role betanin (BET) on cisplatin (Cis)-induced deterioration in mitochondrial indices of functionality. Data are given as mean $\pm S D(n=10)$. aA significant difference compared to control. ${ }^{b} A$ significant difference compared to cis-treated group $(p<0.05)$. 
Betanin $(100 \mathrm{mg} / \mathrm{kg})$ could substantially prohibit mitochondrial toxicity in cisplatin-treated animals (Figures $2 \& 3$ ).

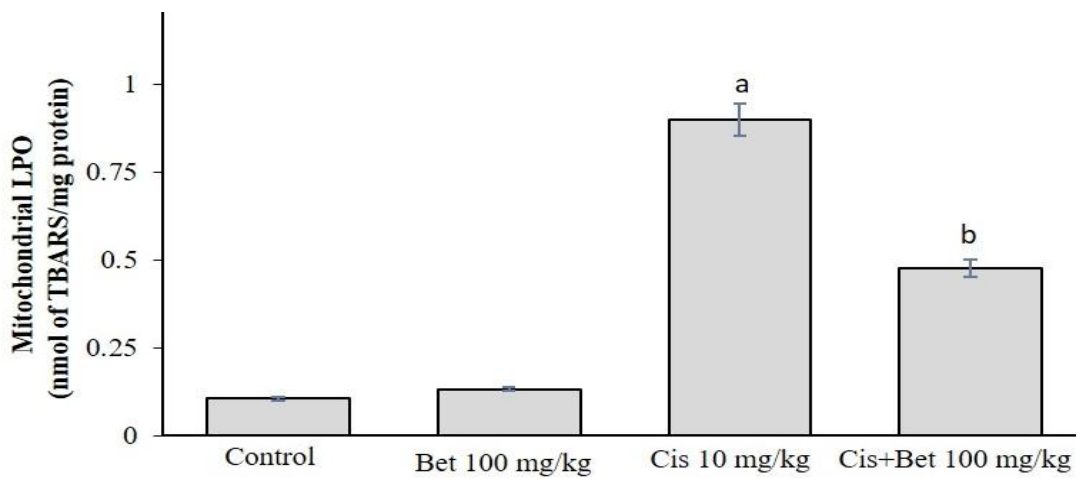

Figure 3. The role betanin (BET) on cisplatin (Cis)-induced lipid peroxidation (LPO) in mitochondrial indices. Data are given as mean \pm SD $(n=10)$. a A significant difference compared to control. $b$ A significant difference compared to cis-treated group. $(\mathrm{p}<0.05)$.

Accordingly, it was speculated that cisplatin might induce the liberation of cytochrome $\mathrm{c}$. As illustrated in Figure 4, there was a statistically significant difference in the amount of cytochrome $\mathrm{c}$ in cisplatin-treated group in comparison with control animals. Betanin decreased the level of cytochrome c in cisplatinadministrated rats (Figure 4).

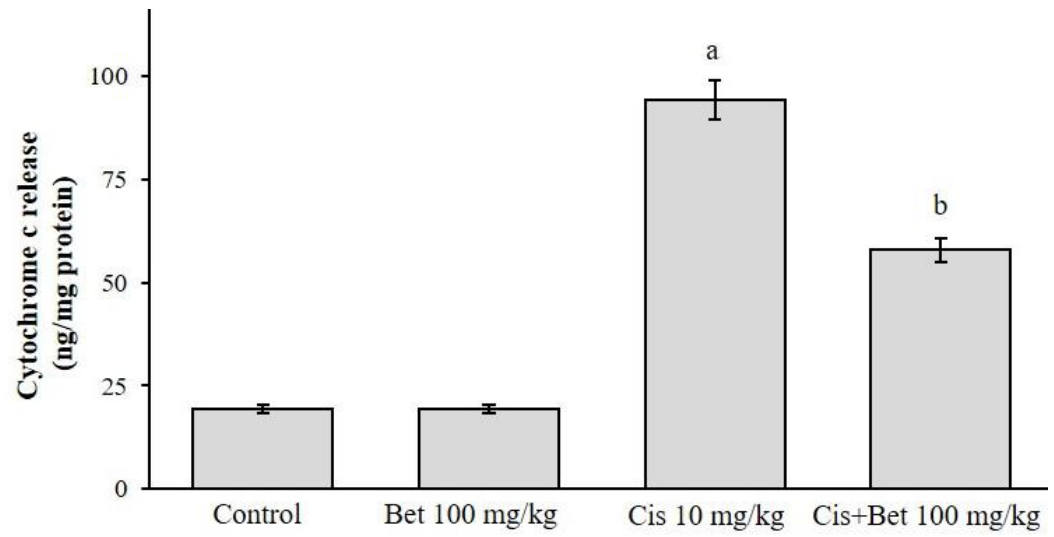

Figure 4. The role betanin (BET) on cisplatin (Cis)-induced cytochrome c release in mitochondrial indices. Data are given as mean $\pm S D\left(n=10\right.$. a A significant difference compared to control. ${ }^{b}$ A significant difference compared to cis-treated group $(\mathrm{p}<0.05)$.

The inhibitory role of betanin in the cytochrome c release suggests the potential role of this chemical in prohibition of mitochondrial permeability transition pore opening.

\section{DISCUSSION}

Cisplatin is a chief anticancer agent used in the treatment of various tumors. However, nephrotoxicity is considered as a major dose-limiting adverse effect in cisplatin prescription [19]. The formation of cisplatinDNA crosslinks results in the cytotoxicity of cancerous and other proliferative cells [20]. It has been shown that proximal tubule cells are selectively affected by cisplatin. The identification of theses renal injuries has been the subject of several in vivo and in vitro studies. The occurrence of oxidative stress, inflammation, and apoptosis has been considered among the possible cytotoxicity mechanisms of cisplatin [21]. Thus, it is required to implement novel models in which the exact mechanisms of cisplatin-induced cell injury are surveyed. Moreover, understanding of the underlying mechanisms provides future directions for clinicians to prevent and/or counteract this toxicity. Mitochondria have been posed as important targets of drug-induced nephrotoxicity [22]. The reabsorption of several chemicals in the kidney tubules is an ATP-dependent process. Thus, renal proximal tubules are rich in mitochondria $[23,24]$ and the $\mathrm{Na}+/ \mathrm{K}+\mathrm{ATPase}$ pump provides the 
energy for the electrochemical sodium gradient in this segment [25]. Vitamins, glucose, phosphate, and low molecular proteins are imported into the proximal tubule cell via the action of the $\mathrm{Na}+\mathrm{K}+\mathrm{ATPase}$ pump and sodium export [26]. Hence, any disturbance in the function of renal mitochondria can disrupt the chemical reabsorption process. In this regard, mitochondrial function is targeted via several xenobiotics and/or drugs $[27,28]$. The results of our study were in line with previous research, which highlight the role of mitochondria in cisplatin-induced renal injury. We found here that mitochondrial ATP level considerably plummeted after cisplatin administration. Moreover, the isolated kidney mitochondria showed deteriorations in the membrane potential status. Thus, mitochondrion is deemed to be involved in the cytotoxicity mechanism of cisplatin, which in turn interferes with chemical reabsorption. This was proved by the alteration in renal function biomarker in the urine samples (high proteinuria and glycosuria). Furthermore, the direct connection of mitochondria and the apoptotic machinery has been documented among the important cytotoxicity mechanisms of cisplatin in kidney [12]. The upregulation of renal tumor necrosis factor- $\alpha$ (TNF- $\alpha$ ), nuclear factor-kappa B(NF-kB) and caspase-3 which are prominent mediators of apoptosis has been observed in cisplatin treated rats. Betanin has significantly reduced the expression of these genes after exposure to cisplatin [8]. Oxidative stress and formation of ROS are the major mechanisms by which cisplatin induces nephrotoxicity. Moreover, cisplatin plunges the endogenous antioxidant defense system including glutathione and nicotinamide adenine dinucleotide phosphate (NADPH) in kidney tissues in vivo [30]. Cisplatin can specifically inhibit respiratory chain complexes I to IV and induce oxidative stress. However, the partial prohibition of cisplatin-induced renal injury via antioxidants proposes the involvement of other mechanisms [29]. Recent studies have pointed towards the role of mitochondrial nitric oxide synthase (mNOX) as a possible cellular event in the renal toxicity of cisplatin. It has been shown that $\mathrm{mNOX}$ and peroxynitrite are significantly up-regulated in the kidney of cisplatin-administrated animals. Cisplatin has resulted in the substantial upregulation on neuronal NOX and elevation of nitrite levels in isolated kidney mitochondria, which can directly influence cellular cytoskeleton and the apoptosis machinery. On the other hand, the use of neuronal inhibitors and peroxynitrite scavengers has substantially counteracted cytotoxicity of cisplatin in this study. Furthermore, 3-morpholinosydnonimine-N-ethylcarbamide (SIN-1) as a peroxynitrite generator has triggered the aforementioned toxic effects by mimicking the effects of cisplatin [30]. We hypothesized that cisplatin induced mitochondrial damages in agreement with prior reports. In addition, considering the deleterious effects of cisplatin on kidney are mediated by mitochondrial dysfunction, this paves the way to introduce novel therapeutic approaches. The protective role of several agents such a carvedilol, quercetin, and naringenin has been investigated against cisplatin-associated nephrotoxicity [30,31,32]. Betanin has been shown to inhibit the nephrotoxic effects of gentamicin through prohibition of oxidative/nitrosative stress. Betanin has significantly decreased the levels of lipid peroxidation, malondealdehyde, catalase, and nitric oxide. This effect was concurrent with the improvement of chemical reabsorption as well as the histopathology of the kidney tissue of gentamicin-administrated animals. Betanin is also effective in attenuations the inflammatory response and apoptosis after gentamicin administration in vivo [33]. In another study, the protective role betanin in paraquat-induced acute kidney injury has been investigated. It was shown that betanin reduced the expression of NOX, cyclooxygenase, and nuclear factor kappa B. Additionally, betanin elicited antioxidant effects and plummeted the lysosomal protease activity in the kidney of paraquat-treated animals [18]. Recent studies have also exhibited the protective effects of betanin in diabetic nephropathy which is characterized by matrix accumulation and renal epithelial cell fibrosis [34]. Betanin revealed anti-fibrotic effects by reduction of mRNA and protein levels of type IV collagen, alpha-smooth muscle actin, transforming growth factor-beta, and E-cadherin. Betanin could also substantially modulate serum and urine factors in the kidney function and restore the cellular antioxidant enzyme activities in the streptozotocin-induced diabetic nephropathy [35]. The results of our study indicated that betanin is an effective chemical in cisplatin-induced nephrotoxicity in particular by reduction of mitochondrial damaged in renal tissue.

\section{CONCLUSION}

The current study provided insights to the possible mechanisms of cisplatin-induced nephrotoxicity in which mitochondrial dysfunction plays a critical role. Our results showed that betanin is protective against cisplatin-induced kidney injury. Betanin presented it protective role via modulation of chemical reabsorption and restoration of mitochondrial function. Thus, betanin might act as a mitochondrial protecting agent against drug/xenobiotic- induced toxicities. However, its role on tricarboxylic acid cycle and the mitochondrial respiratory chains should be also evaluated in the future studies. 


\section{MATERIALS AND METHODS}

\subsection{Chemicals}

Cisplatin, 3-[4,5dimethylthiazol-2-yl]-2,5-diphenyltetrazolium bromide (MTT), Rhodamine123 (Rh 123), sucrose, perchloric acid, D-mannitol, and thiobarbituric acid (TBA) and all other chemicals were obtained from Sigma (Sigma-Aldrich, St. Louis, MO). All salts utilized for preparing buffer solutions were of the analytical grade and purchased from Merck (Merck KGaA, Darmstadt, Germany).

\subsection{Animals and experimental setup}

Male Spague-Dawly rats (200-250g) were obtained from the Tabriz University of Medical Sciences and were housed in an ambient temperature $\left(23^{\circ} \mathrm{C}\right)$ and humidity $(40 \%)$. Animals were fed with standard pellet chow and received tap water. All procedures were done according to the guideline of laboratory animal care approved by the ethical committee of Tabriz University of Medical Sciences. Animals were randomly divided into four groups ( $\mathrm{n}=10$ in each group). Rats were treated as follows: 1) Control (Vehicle-treated group), 2) cisplatin (10 mg/ kg, intraperitoneal (IP)); 3) betanin (100 mg/kg/day, oral); 4) betanin (100 mg/kg/day, oral) + cisplatin $(10 \mathrm{mg} / \mathrm{kg}$, IP). On day 3 of betanin administration, all rats had an IP injection of $10 \mathrm{mg} / \mathrm{kg}$ cisplatin (Sigma, USA) except those in the control and betanin-received groups. After cisplatin administration (72h), all rats were euthanized subsequent to serum and urine specimens' collection. The kidney was also resected in order to isolate renal mitochondria. The doses for cisplatin and betanin were selected based on the previous studies [12,18]. The study protocol was designed and approved by the Ethics Committee for the Use of Animals in Research at Tabriz University of Medical Sciences (No: 91/2-2/5/4 Dec 2012).

\subsection{Serum and urine biochemistry assays}

The urine samples were diluted with cold normal saline after collection. Then a centrifugation step was performed at $1000 \times \mathrm{g}$ for $5 \mathrm{~min}$ and the supernatants were analyzed. Blood samples were collected under ktamin/xylazine $(100 / 10 \mathrm{mg} / \mathrm{kg})$ anesthesia. All serum and blood tests were analyzed using standard laboratory kits. Also, the total body weight and the kidney/ body weigh ration were assessed.

\subsection{Kidney mitochondria isolation}

Differential centrifugation technique was utilized to isolate kidney mitochondria [36]. After the kidney was washed, it was minced in an ice-cold medium consisting of $2 \mathrm{mM}$ HEPES, $70 \mathrm{mM}$ mannitol, $220 \mathrm{mM}$ sucrose, $0.5 \mathrm{mM}$ EGTA and $0.1 \%$ BSA. Then, the buffer was changed and the minced tissue was homogenized with the new medium. The centrifugation $(1000 \times \mathrm{g}, 10 \mathrm{~min})$ was performed three times to yield the mitochondrial fraction. Ultimately, the mitochondrial palate was suspended in the buffer and the Bradford approach was utilized to standardize the protein concentration [37].

\subsection{Mitochondrial dehydrogenases activity}

The activity of mitochondrial dehydrogenase was evaluated through the colorimetric 3-(4, 5dimethylthiazol- 2-yl)-2, 5-diphenyltetrazolium bromide (MTT) assay. Mitochondrial dehydrogenase activity is an important marker for the integrity of the mitochondrial membrane. To do this, the prepared mitochondrial suspension was incubated with a $0.4 \%$ MTT solution for $30 \mathrm{~min}$. Afterwards, the specimens were centrifuged at $16000 \times \mathrm{g}$ for $10 \mathrm{~min}$ and the formed formazan crystals were dissolved in dimethyl sulfoxide and the absorbance was measured at $570 \mathrm{~nm}$ wavelength [38].

\subsection{Mitochondrial swelling}

A spectrophotometric strategy, which monitors the changes in the light absorbance, was utilized to assess the mitochondrial permeabilization at $540 \mathrm{~nm}$. Then, the mitochondrial suspension $(0.5 \mathrm{mg}$ protein $/ \mathrm{mL})$ was suspended in the swelling buffer and the absorbance was measured at $540 \mathrm{~nm}$ during the incubation period. Mitochondrial swelling was in proportion with absorbance decline [39].

\subsection{Mitochondrial depolarization}

The capability of mitochondria to capture the fluorescent dye, rhodamine 123, was utilized in evaluation of the mitochondrial polarization status [40]. The occurrence of mitochondrial damages leads to the accumulation of rhodamine123 in the supernatant since the facilitated diffusion is inhibited [41]. Incubation of rhodamine $123(10 \mu \mathrm{M})$ with $1 \mathrm{mg}$ protein/mL mitochondrial fraction was performed in dark for $30 \mathrm{~min}$. 
Then, the centrifugation of the sample in $15000 \times \mathrm{g}$ was done for $5 \mathrm{~min}$ and the intensity of the dye fluorescent was recorded in the supernatant at emission and excitation wavelength of 525 and $485 \mathrm{~nm}$, respectively [42].

\subsection{Mitochondrial ATP level}

The luciferase assay kit (Biotherma, Sweden) was utilized for measurement of the ATP contents of the isolated mitochondria. The experiment was performed according to the instruction in the kit and the luminescent intensity was observed at $560 \mathrm{~nm}$ [43].

\subsection{Mitochondrial lipid peroxidation}

Peroxidation of the mitochondrial lipids was assessed using thiobarbituric acid-reactive substances (TBARS) examination. After the washing of the isolated mitochondria with an ice-cold buffer (50 mM MOPS, $100 \mathrm{mM} \mathrm{KCl})$, a combination of $1 \mathrm{~mL} \mathrm{HCl}(0.2 \mathrm{~N})$, trichloroacetic acid (15\% w: v), thiobarbituric acid $(0.375 \%$ $\mathrm{w}: \mathrm{v})$, and Trolox $(0.5 \mathrm{mM})$ was added to the suspension. Then, the specimens were heated at $100^{\circ} \mathrm{C}$ water bath for $15 \mathrm{~min}$. Finally, the absorbance was measured at $532 \mathrm{~nm}$ following a centrifugation step $(15000 \times \mathrm{g}, 10$ minutes) [39].

\subsection{Mitochondrial cytochrome $\mathrm{c}$ release}

The experiment was performed according to the manufacturer's guidelines, Sigma-Aldrich Chemical Co (St. Louis, USA). The secondary monoclonal antibody solution that was specific for cytochrome c and conjugated to horseradish peroxidase was added to the mouse/rat cytochrome $\mathrm{c}$ antibody pre-coated microplate. After the addition of the samples ( $1 \mu \mathrm{g}$ protein of each supernatant) and the positive control, the substrate solution was added (after 2 hours). Then, the stop solution was used to terminate the reaction and the absorbance was measured at $450 \mathrm{~nm}[39,43]$.

\subsection{Statistical analysis}

Data are presented as the mean $\pm S D$. The one-way analyses of variance (ANOVA) with Tukey's post hoc test were used for the comparison of the results. $\mathrm{P}<0.05$ was considered as a statistically significant difference.

Acknowledgements: The authors are thankful to the Tabriz University of Medical Sciences “Students' Research Committee" for providing technical supports to the study.

Author contributions: Concept - S.Z., E.A., R.K.; Design - E.A., T.S.; Supervision - M.A., R.K.; Materials - M.A; Data Collection and/or Processing - S.Z., E.A.; Analysis and/or Interpretation - E.A., S.Z., V.T.; Literature Search - S.Z., E.A., R.K.; Writing - E.A.; Critical Reviews - R.K., M.A., S.Z., E.A.

Conflict of interest statement: The authors declared no conflict of interest in the manuscript.

\section{REFERENCES}

[1] Hall A, Bass P, Unwin R. Drug-induced renal Fanconi syndrome. QJM-Int J Med. 2013; 107(4): 261-269. [CrossRef]

[2] Heidari R. The footprints of mitochondrial impairment and cellular energy crisis in the pathogenesis of xenobioticsinduced nephrotoxicity, serum electrolytes imbalance, and Fanconi's syndrome: a comprehensive review. Toxicology. 2019; 423: 1-31. [CrossRef]

[3] Eftekhari A, Hasanzadeh M, Sharifi S, Dizaj SM, Khalilov R, Ahmadian E. Bioassay of saliva proteins: The best alternative for conventional methods in non-invasive diagnosis of cancer. Int J Biol Macromol. 2019; 124: 1246-1255. [CrossRef]

[4] Miller RP, Tadagavadi RK, Ramesh G, Reeves WB. Mechanisms of cisplatin nephrotoxicity. Toxins. 2010; 2(11): 2490518. [CrossRef]

[5] Dasari S, Tchounwou PB. Cisplatin in cancer therapy: molecular mechanisms of action. Eur J Pharmacol. 2014; 740: 364-378. [CrossRef]

[6] Ali BH, Al Moundhri MS. Agents ameliorating or augmenting the nephrotoxicity of cisplatin and other platinum compounds: a review of some recent research. Food Chem Toxicol. 2006; 44(8): 1173-1183. [CrossRef]

[7] Meng XM, Li HD, Wu WF, Tang PM, Ren GL, Gao L, Li XF, Yang Y, Xu T, Ma TT, Li Z. Wogonin protects against cisplatin-induced acute kidney injury by targeting RIPK1-mediated necroptosis. Lab Invest. 2018; 98(1): 79. [CrossRef] 
[8] Hagar H, ElMedany A, Salam R, El Medany G, Nayal OA. Betaine supplementation mitigates cisplatin-induced nephrotoxicity by abrogation of oxidative/nitrosative stress and suppression of inflammation and apoptosis in rats. Exp Toxicol Pathol. 2015; 67(2): 133-141. [CrossRef]

[9] Matsushima H, Yonemura K, Ohishi K, Hishida A. The role of oxygen free radicals in cisplatin-induced acute renal failure in rats. J Lab Clin Med. 1998; 131(6): 518-526. [CrossRef]

[10] Fariss MW, Chan CB, Patel M, Van BH, Orrenius S. Role of mitochondria in toxic oxidative stress. Mol Interv. 2005; 5(2): 94-111. [CrossRef]

[11] Ahmadian E, Babaei H, Nayebi AM, Eftekhari A, Eghbal MA. Mechanistic approach for toxic effects of bupropion in primary rat hepatocytes. Drug Res. 2017; 67(04): 217-222. [CrossRef]

[12] Rodrigues MC, Rodrigues J, Martins N, Barbosa F, Curti C, Santos N, Santos AC. Carvedilol protects against cisplatininduced oxidative stress, redox state unbalance and apoptosis in rat kidney mitochondria. Chem-Biol Interact. 2011; 189(1-2): 45-51. [CrossRef]

[13] Ahmadian E, Khosroushahi AY, Eghbal MA, Eftekhari A. Betanin reduces organophosphate induced cytotoxicity in primary hepatocyte via an anti-oxidative and mitochondrial dependent pathway. Pestic Biochem Physiol. 2018; 144: 71-78. [CrossRef]

[14] Yadi M, Mostafavi E, Saleh B, Davaran S, Aliyeva I, Khalilov R, Nikzamir M, Akbarzadeh A, Panahi Y, Milani M. Current developments in green synthesis of metallic nanoparticles using plant extracts: a review. Artif Cell Nanomed B. 2018; 46(sup3): S336-S43. [CrossRef]

[15] Farshbaf M, Salehi R, Annabi N, Khalilov R, Akbarzadeh A, Davaran S. PH-and thermo-sensitive MTX-loaded magnetic nanocomposites: synthesis, characterization, and in vitro studies on A549 lung cancer cell and MR imaging. Drug Dev Ind Pharm. 2018; 44(3): 452-462. [CrossRef]

[16] Khalilov R, Ahmadov IS, Kadirov SG. Two types of kinetics of membrane potential of water plant leaves illuminated by ultraviolet light. Bioelectrochemistry. 2002; 58(2): 189-191. [CrossRef]

[17] Gol'dfel'd MG, Khalilov RI. Localization of copper in the photosynthetic apparatus of chloroplasts. Biofizika. 1979; 24(4): 762-4.

[18] Tan D, Wang Y, Bai B, Yang X, Han J. Betanin attenuates oxidative stress and inflammatory reaction in kidney of paraquat-treated rat. Food Chem Toxicol. 2015; 78: 141-146. [CrossRef]

[19] Yao X, Panichpisal K, Kurtzman N, Nugent K. Cisplatin nephrotoxicity: a review. Am J Med Sc. 2007; 334(2): 115-124. [CrossRef]

[20] Kafshdooz L, Pourfathi H, Akbarzadeh A, Kafshdooz T, Razban Z, Sheervalilou R, Ebrahimi Sadr N, Khalilov R, Saghfi S, Kavetskyy T, Mammadova L. The role of microRNAs and nanoparticles in ovarian cancer: a review. ARTIF CELL NANOMED B. 2018; 46(sup2): 241-247. [CrossRef]

[21] Manohar S, Leung N. Cisplatin nephrotoxicity: a review of the literature. Journal of nephrology. 2018; 31(1): 15-25. [CrossRef]

[22] Santos N, Catao C, Martins N, Curti C, Bianchi MdLP, Santos ACd. Cisplatin-induced nephrotoxicity is associated with oxidative stress, redox state unbalance, impairment of energetic metabolism and apoptosis in rat kidney mitochondria. Arch Toxicol. 2007; 81(7): 495-504. [CrossRef]

[23] Shaik ZP, Fifer EK, Nowak G. Akt activation improves oxidative phosphorylation in renal proximal tubular cells following nephrotoxicant injury. Am J Physiol Renal Physiol. 2008; 294(2): F423-F32. [CrossRef]

[24] Soltoff SP, Mandel LJ. Active ion transport in the renal proximal tubule. III. The ATP dependence of the Na pump. J GEN PHYSIOL. 1984; 84(4): 643-662. [CrossRef]

[25] You G. Structure, function, and regulation of renal organic anion transporters. Med Res Rev. 2002; 22(6): 602-616. [CrossRef]

[26] Rahgozar M, Willgoss DA, Gobé GC, Endre ZH. ATP-dependent K+ channels in renal ischemia reperfusion injury. Renal Fail. 2003; 25(6): 885-896. [CrossRef]

[27] Eftekhari A, Dizaj SM, Chodari L, Sunar S, Hasanzadeh A, Ahmadian E, Hasanzadeh M. The promising future of nano-antioxidant therapy against environmental pollutants induced-toxicities. Biomed Pharmacother. 2018; 103: 1018-1027. [CrossRef]

[28] Ahmadian E, Khosroushahi AY, Eftekhari A, Farajnia S, Babaei H, Eghbal MA. Novel angiotensin receptor blocker, azilsartan induces oxidative stress and NFkB-mediated apoptosis in hepatocellular carcinoma cell line HepG2. Biomed Pharmacother. 2018; 99: 939-946. [CrossRef] 
[29] Cummings BS, Schnellmann RG. Cisplatin-induced renal cell apoptosis: caspase 3-dependent and-independent pathways. J Pharmacol Exp Ther. 2002; 302(1): 8-17. [CrossRef]

[30] Jung M, Hotter G, Viñas JL, Sola A. Cisplatin upregulates mitochondrial nitric oxide synthase and peroxynitrite formation to promote renal injury. Toxicol Appl Pharmacol. 2009; 234(2): 236-246. [CrossRef]

[31] Badary OA, Abdel-Maksoud S, Ahmed WA, Owieda GH. Naringenin attenuates cisplatin nephrotoxicity in rats. Life Sci. 2005; 76(18) :2125-2235. [CrossRef]

[32] Aldemir M, Okulu E, Kösemehmetoğlu K, Ener K, Topal F, Evirgen O, Gürleyik E, Avc1 A. Evaluation of the protective effect of quercetin against cisplatin- induced renal and testis tissue damage and sperm parameters in rats. Andrologia. 2014; 46(10): 1089-97. [CrossRef]

[33] Clifford T, Howatson G, West D, Stevenson E. The potential benefits of red beetroot supplementation in health and disease. Nutrients. 2015; (4): 2801-22. [CrossRef]

[34] Gross JL, De Azevedo MJ, Silveiro SP, Canani LH, Caramori ML, Zelmanovitz T. Diabetic nephropathy: diagnosis, prevention, and treatment. Diabetes Care. 2005; 28(1): 164-76. [CrossRef]

[35] Sutariya B, Saraf M. Betanin, isolated from fruits of Opuntia elatior Mill attenuates renal fibrosis in diabetic rats through regulating oxidative stress and TGF- $\beta$ pathway. J Ethnopharmacol. 2017; 198: 432-43. [CrossRef]

[36] Fernández-Vizarra E, Ferrín G, Pérez-Martos A, Fernández-Silva P, Zeviani M, Enríquez JA. Isolation of mitochondria for biogenetical studies: An update. Mitochondrion. 2010; 10(3): 253-62. [CrossRef]

[37] Bradford MM. A rapid and sensitive method for the quantitation of microgram quantities of protein utilizing the principle of protein-dye binding. Anal Biochem. 1976; 72(1-2): 248-54. [CrossRef]

[38] Heidari R, Mandegani L, Ghanbarinejad V, Siavashpour A, Ommati MM, Azarpira N, Najibi A, Niknahad H. Mitochondrial dysfunction as a mechanism involved in the pathogenesis of cirrhosis-associated cholemic nephropathy. Biomed Pharmacother. 2019; 109: 271-80. [CrossRef]

[39] Caro AA, Adlong LW, Crocker SJ, Gardner MW, Luikart EF, Gron LU. Effect of garlic-derived organosulfur compounds on mitochondrial function and integrity in isolated mouse liver mitochondria. Toxicol Lett. 2012; 214(2): 166-74. [CrossRef]

[40] Eftekhari A, Ahmadian E, Azami A, Johari- Ahar M, Eghbal MA. Protective effects of coenzyme Q10 nanoparticles on dichlorvos- induced hepatotoxicity and mitochondrial/lysosomal injury. Environ Toxicol. 2018; 33(2): 167-77. [CrossRef]

[41] Ahmadian E, Eftekhari A, Babaei H, Nayebi A, Eghbal M. Anti-cancer effects of citalopram on hepatocellular carcinoma cells occur via cytochrome C release and the activation of NF-kB. Anticancer Agents Med Chem. 2017; 17(11): 1570-7. [CrossRef]

[42] Eftekhari A, Ahmadian E, Azarmi Y, Parvizpur A, Fard JK, Eghbal MA. The effects of cimetidine, N-acetylcysteine, and taurine on thioridazine metabolic activation and induction of oxidative stress in isolated rat hepatocytes. Pharm Chem J. 2018; 51(11): 965-9. [CrossRef]

[43] Sukkurwala AQ, Adjemian S, Senovilla L, Michaud M, Spaggiari S, Vacchelli E, Baracco EE, Galluzzi L, Zitvogel L, Kepp O, Kroemer G. Screening of novel immunogenic cell death inducers within the NCI Mechanistic Diversity Set. Oncoimmunology. 2014; 3(4): e28473. [CrossRef] 